\title{
Mathematical modeling of clinical engineering approach to evaluate the quality of patient care
}

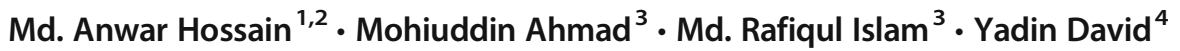

Received: 25 September 2019 / Accepted: 15 October 2019 / Published online: 24 November 2019

(C) IUPESM and Springer-Verlag GmbH Germany, part of Springer Nature 2019

\begin{abstract}
At present, the patient care delivery system (PCDS) in a hospital/medical institute/clinic is absolutely medical technologydependent and this tendency is found to increase day by day. To ensure the quality of patient care (QPC) appropriate implementation of the patient care technology management system (PCTMS) is necessary. Unfortunately, it is found to be absent in the healthcare delivery system in most of the countries in the world. The situation is very much severe, particularly, in medium- and low-income countries like Malaysia, India, Sri Lanka, Bangladesh, Pakistan, etc. The opposite scenario is found in high-income countries, specifically, in Japan where QPC has been improved significantly by adopting the clinical engineering approach (CEA) in their PCDS. Up to now, QPC is determined based on prediction as there are no mathematical ways to evaluate it properly. In this study, we for the first time, propose a mathematical model to evaluate the QPC quantitatively based on feedback control analogy taking into account of CEA in PCTMS, particularly, for clinical and surgical equipment. The model consists of three subsections: the clinical engineering department (CED), PCTMS, and health care engineering directorate (HCED). The correlation among the subsections and their performance parameters are defined and standardized. Multiple linear regression method is applied to derive the least square normal equations for each of the subsections and then the regression coefficients are solved by the standard data taken from 1000 beds hospitals of different countries. The model is applied to reveal the present status of QPC for 18 different countries including high-, middle-, and low-income countries of the world. The results obtained from the model demonstrate that the present status of QPC in Japan is $84.69 \%$ and in Pakistan, it is only $0.20 \%$. This huge discrepancy is identified to be caused by the inclusion of CEA in PCDS of Japan. The proposed model can be applied to evaluate the QPC of a hospital/in a country and hence to take necessary steps accordingly for establishing the proposed research methodology. It is to be mentioned here that the proposed model cannot be applied to evaluate the QPC in some countries like Bangladesh, Bhutan, Nepal, etc. due to the unavailability of data related to the model parameters.
\end{abstract}

Keywords CED $\cdot$ PCDS $\cdot$ PCTMS $\cdot$ QPC $\cdot$ Modern hospital $\cdot$ Medical and surgical equipment $\cdot$ patient safety $\cdot$ and cost-effective care

\section{Introduction}

Nowadays, the quality of the patient care delivery system (PCDS), particularly, disease diagnosis and treatment are

Md. Anwar Hossain

anwar.bme@gmail.com

Mohiuddin Ahmad

ahmad@eee.kuet.ac.bd

Md. Rafiqul Islam

islambit@yahoo.com

Yadin David

david@biomedeng.com mostly medical device-dependent [1]. In the meantime, the development of patient care delivery is found significant in different countries [2]. However, the quality of patient care (QPC) allied with the performance outcomes of medical and

1 Department of Biomedical Engineering, Khulna University of Engineering \& Technology (KUET), Khulna 9203, Bangladesh

2 National Electro-Medical Equipment Maintenance Workshop \& Training Center, MoH \& FW, Dhaka, Bangladesh

3 Department of Electrical and Electronic Engineering, Khulna University of Engineering \& Technology (KUET), Khulna 9203 , Bangladesh

4 Biomedical Engineering Consultants, LLC, Houston, TX, USA 
surgical equipment has not been explored yet in detail [3]. The patients' satisfaction absolutely depends on the QPC and can be achieved by reduction of risk factors (patient injuries, unnatural patients' deaths, etc.) caused by medical and surgical equipment under medical conditions [2, 4]. The risk factors associated with medical devices are studied by Hossain et al. [5]. It is found that the patients' risk factors can be reduced by applying engineering and managerial skills to healthcare technology by means of clinical engineering approach (CEA) [5, 6]. In this study, the performance of patient care is investigated in terms of the performance outcomes of healthcare technology considering its five key parameters that is why the term health technology management system can be used as a patient care technology management system (PCTMS) [7]. It is noted that high-income countries like Japan, Belgium, America, etc., already adopted CEA in their patient care technology management system (PCTMS). Consequently, patient safety and effective care of these countries are found to improve significantly than that of many upper-middle and lowermiddle-income countries like Malaysia, South Africa, Indonesia, Bangladesh, Bhutan, Nepal, etc. [8,9]. The PCDS of developing countries are found inferior from a study conducted by Hossain et al. [5]. In this study, the role of clinical engineers for improving the health care technology management system is pointed out. It is well established that without CEA in PCTMS it is not possible to improve QPC.

It is found in [9] that Japan in the meantime significantly improved QPC by implementing CEA in PCTMS. There are no straight forward standard ways to establish a clinical engineering department (CED) in a hospital. In Japanese hospitals, CEDs are formed with the excess number of employees, so their approach is costly. On the other hand, some countries like Jordan, South Africa, India, etc. established CEDs with an insufficient number of employees. Contrary to that some countries (Indonesia, Bangladesh, Bhutan, Nepal, etc.) are providing patient care services without establishing CEDs in their hospitals [8]. To best of our knowledge, there is no mathematical model to evaluate QPC quantitatively taking into account of CEA in PCDS.

Here we have proposed a mathematical model to evaluate the QPC quantitatively based on feedback control theory. The model mainly consists of three subsections: CED, PCTMS, and health care engineering directorate (HCED). Here, we have proposed a cost-effective model for CED as well as for HCED which will act as a regulatory authority of PCTMS. The performance parameters of each subsection are defined and their characteristics are explained. Using multiple linear regression equations, the standard performance equations of $\operatorname{CED}\left(G_{\mathrm{P}}\right)$, PCTMS $\left(A_{\mathrm{P}}\right)$ and HCED $\left(A_{\mathrm{F}}\right)$ are proposed and then least-square normal equations are derived. The regression coefficients of these equations are solved by using the standard data collected from 1000 beds in modern hospitals having different types of medical equipment users departments [9,
10]. The model is applied to evaluate the QPC of different countries with CEDs and without CEDs. The results obtained from the model clearly demonstrate that the QPC of the countries where the appropriate implementation of PCTMS is performed by CEDs found to be at a satisfactory level, that is, in case of Japan, it is $84.69 \%$. On the other hand, it is found to be at a marginal level, that is, $53.14 \%$ and $52.10 \%$, respectively, for Slovene (SVN) and Belgium (BEL). For some countries like India, Pakistan, Jordan, South Africa, Bhutan, Maldives, Nepal, etc. the value of QPC is very poor and even it is not possible to evaluate the QPC for some countries like Bangladesh, Myanmar, Sri-Lanka due to unavailability of model data in their hospitals $[8,11]$.

Our findings must encourage biomedical engineering professionals, medical professionals, healthcare policymakers, equipment users, local vendors, etc., for establishing the proposed research methodology and hence to add clinical engineering professionals in PCTMS in a hospital for ensuring the QPC. The remaining parts of this paper are organized as follows: in section 2 concepts of the model and its key parameters are described; section 3 describes the proposed research methodology; mathematical formulations and methods are explained in section. Finally, the recommendation and conclusion of this study are presented in sections 5 and 6, respectively. Acknowledgments, references, related definitions, and terminologies, etc., have shown in appendix A.

\section{Related works}

\subsection{Key parameters of QPC and their correlation with standard parameters of PCTMS}

QPC depends on six parameters as reported so far [2]. But, the Institute of Medicine (IOM) mentioned that the components of quality-care can be defined on the conceptual components rather than the measured indicators, that is, it must be safe, effective, patient-centered, timely, efficient, and equitable. Thus safety is the foundation upon which all other aspects of quality-care are built $[1,12,13]$. Since our main objective is to ensure patient safety, it is considered as a key parameter to evaluate the QPC. The patient safety, on the other hand, depends on the appropriate application of PCTMS, that is, on the performance outcomes of medical and surgical equipment. According to the definition of IOM, patient safety is the prevention of harm to patients $[6,14]$. In the patient safety network website, the Agencies for Healthcare Research and Quality (AHRQ) have defined the term "prevention of harm" as "freedom from accidental or preventable injuries produced by medical care" [6]. From the above statements, it is cleared that the prevention of harm to patients' is the reduction of risk factors related to medical and surgical equipment. 
There are different types of risk factors that must be distinguished from each other by developing prevention initiatives planning $[5,6]$. In this study, we deal with the prevention of harm that is associated with the incorrect operation, error-full data, and instant failure of life recovery, therapeutic, monitoring of physiological parameters of the human body that can be addressed as surgical and medical equipment. To prevent the harm associated with medical and surgical equipment, it is required to keep the medical equipment in safe and functional conditions, which can be achieved by ensuring a scheduled life span in compliance with the standard life span recommended by the manufacturers. It is found in $[11,14,15]$ that these are the unique outcomes that can be obtained through the appropriate application of PCTMS.

\subsection{Key parameters of PCTMS and their correlation with the quality model of CED}

To ensure the scheduled life span of medical equipment recommended by the manufacturer, it is very much important to keep the management coefficient of the equipment in a safe functional condition [15]. This can be done by introducing CEA in PCTMS, that is, with the quality outcome of the CED model [11]. Standard clinical equipment management coefficients depend on the preventive maintenance (PM) score, risk score, and functionality score of medical and surgical equipment that are used for ensuring the quality of patient care. These scores are medical equipment dependent. A common formula is used in previous studies $[11,15]$ to define the maximum score for different types of medical equipment that have been actively used for patient care. In this study, we consider 10 numbers of equipment including four categories (diagnostic, therapeutic, life recovery and monitoring). As an example, the maximum management coefficient score of a cardiac defibrillator is 20 and the safe score is 16 [15]. When this score goes above 16 , it is required to perform the performance evaluation test of this equipment every six months' interval as PM for achieving the safety and timely outcomes from PCTMS [15]. However, these outcomes are highly dependent on the performance outcome of CED [11, 16]. Applying PM methodologies, the risk factors of equipment can be minimized and thus patient safety can be ensured. So the quality outcomes of CED are strongly dependent on the appropriate number of skilled staffs of CED model, which depends on the numbers of medical equipment, complexity of equipment, and the intensity of medical equipment technology ability in a modern hospital $[11,16,17]$, that is, on the workload of the hospital. The number of skilled staff in the CED of a hospital absolutely depends on the number of medical and surgical equipment rather than the patient's capacity of a hospital [9, 11, 13]. Here we have considered manpower setup for the CED of different level of hospitals (10001500 beds) having 108 to 325 staffs with the following designations: Director clinical engineering (DCE), Senior clinical engineer (Sr. CE), Assistant clinical engineer (ACE), Clinical engineering technologist (CET), and Biomedical equipment technician (BMET) $[9,18]$ to ensure $24 \mathrm{~h}$ services. It is to be noted that the skills of staff are determined by some core indicators such as educational qualification, CE certification, training, and duration of working experiences in this field $[18,19]$.

\subsection{Performance of regulatory authority and its relationship with PCTMS}

A regulatory authority is an autonomous authority or agency established by a federal state or provincial government. The regulatory authority is established with the power to enforce regulations regarding occupational health and safety [20-21]. According to the statement of regulatory authority, the standard performance outcome of PCTMS is necessary at the national level. In this study, an HCED (healthcare engineering directorate) is proposed as a regulatory authority that regulates the performance of PCTMS to ensure the QPC [22-23]. The regulatory authority formed by highly skilled clinical engineers such as Chief CE, Principle CE, Senior CE, and Basic grade CE [18-19]. According to data in [18-19], and human resources for directorate general of health services (DGHS), four constant parameters can be considered for developing a standard model of HCED. These include (i) a chief clinical engineer (CCE), (ii) a director of clinical engineering (DCE), (iii) a clinical engineering manager (CEM), and (iv) a senior clinical engineer (Sr. CE). The number of staff in HCED depends on the workload, that is, the total number of modern hospitals in a country/the total number of medical and surgical equipment/the total numbers of staff in different CEDs under the healthcare system of a country [8-9, 23-24]. These data are necessary to develop a standard model of HCED as well as to evaluate the performance of HCED for ensuring the standard on-time response indicator.

\subsection{Concept to enhance QPC}

It is found in [2] that the QPC mainly depends on six parameters. Alternatively, Cope et al. [1] mentioned that patient safety is the foundation upon which all other aspects of quality-care are built. It is therefore very much important to ensure patient safety to evaluate the QPC. To confirm patient safety, it is required to keep medical equipment in safe \& functional condition by implementing appropriate PCTMS as mentioned by Hossain [11] and Sezdi [15]. There is a strong correlation among the PCTMS, CED, and HCED, which is presented in Fig. 1. To ensure patient satisfaction medical devices must be safe, functional, and timely interfaced with the patient as seen in Fig. 1. These, in turn, depend on the appropriate activities of CED for implementing the PCTMS. 
Fig. 1 Concept of the patient-care PCTMS system considering CEA in

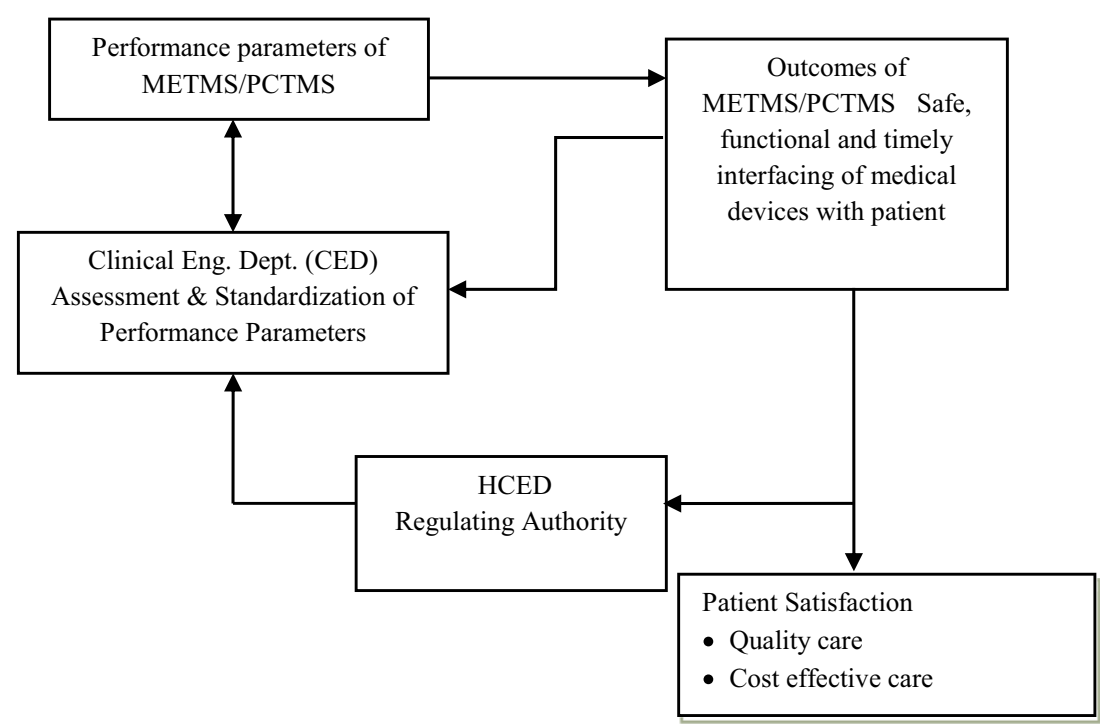

Based on the outcome of patient satisfaction with a regulatory authority, herein, HCED must provide necessary inputs to the CED of a modern hospital for ensuring QPC.

PCTMS is somehow related to clinical equipment management coefficients, which are different for different equipment and depend on three factors such as equipment functional score, equipment risk score, and preventive maintenance (PM) score [15, 25]. These scores are listed in Tables 1, 2, and 3, respectively, and are required to ensure the outcome of PCTMS.

From Tables 1, 2, and 3, it can be noted that it is very much necessary to keep the PM score as 5 and risk score as 1 . By applying this method the standard score point regarding the safe functionality of medical devices can be ensured and that is related to patient safety. To ensure the performance outcomes of patient care in terms of the performance outcomes of PCTMS, a schematic diagram is shown in Fig. 1.

It is found that the QPC completely depends on the performance parameters of CED, PCTMS, and HCED [9, 11]. To best of our knowledge, there is no mathematical way to

Table 1 Device function and corresponding score. The score depends on the importance of a device

\begin{tabular}{ll}
\hline Point & Devices function \\
\hline 10 & Life Recovery Devices \\
9 & Surgical and Intensive Care Devices \\
8 & Physical Therapy Devices \\
7 & Surgical and Intensive Care Patient Monitoring Devices \\
6 & Other Physiological Monitors \\
5 & Analytical Laboratory Devices \\
4 & Laboratory Equipment and Supplies \\
3 & Computers \\
2 & Devices that belong to the patients \\
\hline
\end{tabular}

evaluate the QPC quantitatively using these performance parameters. So there is a research scope to develop a mathematical model for quantitative evaluation of QPC using CEA. In this research work, a concept is proposed to select standard parameters of CED based-on hospital data. The parameters of CED, PCTMS, and HCED can be standardized through data collection, data analysis, etc. using mathematical study.

\section{Proposed mathematical model}

Nowadays disease diagnosis and thereby its treatment entirely depends on medical devices. For improving QPC medical devices must be safe, functional, and timely interfaced with the patient, which can be ensured by duly implementation of PCTMS through CED in a hospital. Based on patient satisfaction level, a regulatory authority, herein HCED, must provide necessary inputs to CED so that QPC can be achieved up to the desired level. These work sequences are presented in Fig. 1 and can be expressed by feedback control theory according to the block diagram shown in Fig. 2 [11, 26]. From Fig. 2, we developed a mathematical model whose performance parameters are represented by $A_{P}, G_{B}$ and $A_{F}$ to express the performances of PCTMS, CED, and HCED, respectively. Here, we also represented input and output performances of CED $\left(A_{p}\right)$

Table 2 Types of risk and corresponding Risk score [25] 
Table 3 Preventive maintenance (PM) score depends on importance [25]

\begin{tabular}{ll}
\hline Point & Importance of device \\
\hline 5 & Very important \\
4 & Moderately important \\
3 & Less important \\
2 & Least important \\
1 & Minimally important \\
\hline
\end{tabular}

by $A_{I}$ and $A_{0}$ and for the PCTMS $\left(G_{P}\right)$, the same is represented by $A_{0}$ and $C_{p}$. Here, $F_{0}$ is the output performance of HCED $\left(A_{F}\right)$ and it can be considered as a feedback factor that regulates reference input as well as the input of PCTMS. Moreover, $R_{P}$ is the desired expectation of a patient, which is set as the input of the proposed system and $C_{p}$ is the actual output of the system. The QPC, that is, the satisfaction level of a patient depends on $C_{p}$.

Applying closed-loop transfer function, the performance of the proposed system shown in Fig. 2 can be represented by Eq. (1).

$C_{P}=\left[\frac{A_{p} G_{p}}{1+A_{p} G_{p} A_{F}}\right] \times R_{p}=H \times R_{P}$

Equation (1) is derived using the following relationship of the system parameters: $A_{0}=A_{I} \times A_{P}, F_{0}=C_{P} \times A_{F}$, and $A_{I}=$ $R_{P}-F_{0}=R_{P}-C_{P} \times A_{F}$. Here, $H$ is referred to as the closedloop transfer function of the system. The numerator of $H$ is the forward (open-loop) gain and the denominator is the so-called loop gain. If $A_{\mathrm{P}} \times G_{\mathrm{P}}>>1$ i.e., it is usually standard and if $\left[A_{\mathrm{F}}\right] \cong 1$ then $C_{P}$ is approximately equal to $R_{P}$ and the output closely tracks the reference input. It is noted that in the case of a closed-loop feedback system a portion of the output is feedback to the input to reduce error and improve system stability. In the present research methodology since human engineering error (risk factor) from a medical device is involved, a closed-loop feedback system is considered to solve the problem.

A patient enters into a hospital with the expected quality of care, which is considered as an input variable, that is, termed as patient satisfaction, $R_{\mathrm{P}}$ and it must be set in the model. From Eq. (1) it is cleared that the standard value of $A_{\mathrm{F}}=1$ to ensure the QPC. The value of $A_{\mathrm{F}}=1$ means that the HCED (regulatory authority) already taken on-time necessary action so that medical device has been interfaced timely with the patient under safe and functional conditions. The value of $A_{\mathrm{F}}>1$ indicates that the HCED has not taken necessary action promptly; as a result, a faulty/partially faulty medical device has been interfaced with the patient. Consequently, the value of $C p$ (patient satisfaction) goes down to the expected level. The correlation of different performance parameters used in Eq. (1) is shown in Table 4 on account of the weight variation from 1 to 5. It found from Table 1 that the output performance, that is, patient satisfaction level, $C_{\mathrm{P}}$ is highly related to the expected performance of the patient, which must have $100 \%$. The other performances $G_{\mathrm{P}}$ and $A_{\mathrm{P}}$, that is, the performances of CED and PCTMS are the prime dominating factor to achieve patient satisfaction at the desired level. It is therefore cleared from Table 4 that there is a strong correlation of QPC with the individual performance of each subsection of the proposed model. It is also justified that the feedback control approach can be applied to evaluate the QPC quantitatively. In the next section, we will discuss how to standardize the performance parameters of $G_{\mathrm{P}} A_{\mathrm{P}}$, and $A_{\mathrm{F}}$.

From Table 4, the relationship between the predicted performance of HCED and the on-time response indicator of $A_{\mathrm{F}}$ is given in Eq. (2) with $96 \%$ satisfaction.

$y=7.18-0.144 x+8.4 \times 10^{-4} x^{2}$

\subsection{Standard performance parameters of $G_{\mathrm{P}}, A_{\mathrm{P},}$ and $A_{\mathrm{F}}$}

Mostly the performances of $G_{\mathrm{P}}, A_{\mathrm{P}}$ and $A_{\mathrm{F}}$ depend on the score of parameters of the respective subsection of the proposed system. To predict the standard score, it is required to collect data from a country where methodologies of advanced CEA already been applied for reducing the undesired events such as patient injuries, and even unnatural deaths of patients related to medical and surgical equipment. From a report published by WHO in 2017 [8], it is found that Japan already established CEA in their hospitals. According to the data, the density of the hospital with CED is 3.5 for 10,000 populations $[8,9]$.

\subsubsection{Determination of standard performance parameters of $G_{P}$}

Performance measurement duration of a device is determined by the device management coefficient which is termed as
Fig. 2 A schematic block diagram of the prospered research methodology

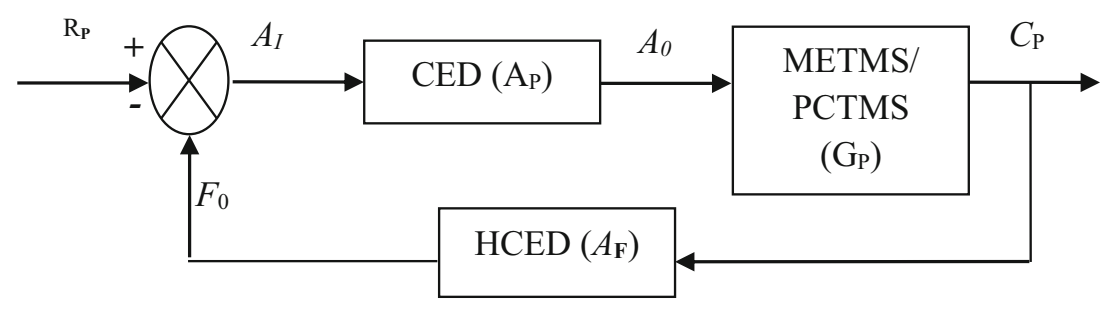


Table 4 The measured value of $C_{\mathrm{P}}$ for different set-point of $A_{\mathrm{F}}$

\begin{tabular}{|c|c|c|c|c|c|}
\hline SL\# & $\begin{array}{l}\text { Predicted Performance } \\
\text { of HCED, } x(\%)\end{array}$ & $\begin{array}{l}\text { On-time response } \\
\text { indicators of } A_{\mathrm{F}}, y\end{array}$ & $\begin{array}{l}\text { Patient expectation } \\
R_{\mathrm{P}}(\%)\end{array}$ & $K=A_{\mathrm{P}} \times G_{\mathrm{P}}$ & $\begin{array}{l}\text { Patient satisfaction level, } \\
C_{P}=\left[\frac{K}{1+K}\right] \times R_{p} \%\end{array}$ \\
\hline 1 & 100 & 1 & 100 & $K$ & $K /(1+K) \times 100$ \\
\hline 2 & 90 & 1.112 & 100 & $K$ & $K /(1+1.112 K) \times 100$ \\
\hline 3 & 80 & 1.25 & 100 & $K$ & $K /(1+1.25 K) \times 100$ \\
\hline 4 & 70 & 1.423 & 100 & $K$ & $K /(1+1.423 K) \times 100$ \\
\hline 5 & 60 & 1.666 & 100 & $K$ & $K /(1+1.667 K) \times 100$ \\
\hline 6 & 50 & 2.00 & 100 & $K$ & $K /(1+2 K) \times 100$ \\
\hline 7 & 40 & 2.50 & 100 & $K$ & $K /(1+2.5 K) \times 100$ \\
\hline 8 & 30 & 3.33 & 100 & $K$ & $K /(1+3.33 K) \times 100$ \\
\hline 9 & 20 & 5 & 100 & $K$ & $K /(1+5 K) \times 100$ \\
\hline
\end{tabular}

clinical equipment management coefficient in the standard of technology \& safety management series proposed by Fennigkoh et al. [25] and it was also supported by Sezdi in [19]. The equation of the clinical equipment management coefficient, $E_{C E M C}$ can be given [15] by Eq. (3).

$E_{C E M C}=E_{F}+E_{R}+E_{P M}$

where $E_{\mathrm{F}}=$ equipment functional score, $E_{\mathrm{R}}=$ equipment risk score, and $E_{\mathrm{PM}}=$ equipment $\mathrm{PM}$ score. Among these $E_{F}$ and $E_{P M}$ are constants coefficients and $E_{\mathrm{R}}$ is variable coefficients, which implies that $E_{C E M C}$ is also variable and it depends on the category of medical and surgical equipment $[15,25]$. This is clearly understood from the scores of $E_{C E M C}$ along with $E_{F}$, $E_{R}$, and $E_{\mathrm{PM}}$ of different medical devices listed in Table 5 and Table 6 under unsafe and safe conditions, respectively. The details are shown in Tables 1, 2, and 3 respectively.

It is found that the standard safe $E_{\mathrm{CEMC}}$ score is less than 16 and it is considered as the highest set-point under patient safety care condition. It is necessary to ensure the performance evaluation test for every six-month interval when this score becomes more than 15 . This can be duly implemented by applying clinical engineering methodologies by CED whose responsibility is to develop and maintain a schedule of preventive maintenance (PM) and do it timely. Thus, patient risk factors such as patient injury and unnatural death related to medical and surgical equipment can be reduced significantly. The performance evaluation test and audit belong to the PM, inspection and appetence test. Additionally, incorrect operation and instant failures of medical and surgical equipment are serious causes for unusual patient injury as well as unnatural death of patients during care conditions.

Clinical engineering methodologies develop skilled staff such as medical professionals, nurses through continuous in-service education and training. Nowadays, clinical engineering technologist (CET) and health care technologist ensure the safe operation by the reduction of incorrect settings and prevention of instant failures of medical and surgical equipment. It is found [11, 15, 25] that performance evaluation, PM, inspection \& acceptance test, safety operation, and continuous in-service education \& training are the key parameters of PCTMS $\left(G_{\mathrm{P}}\right)$. Evaluation of $G_{\mathrm{P}}$ performance is essential for controlling its parameters appropriately. But, performance evaluation by conventional methods is timeconsuming and very expensive. The statistical model to determine the performance using major $G_{\mathrm{P}}$ losses is explained below.

Always there is a chance of equipment failure, so PCTMS must be implemented carefully. Continuous monitoring of $G_{\mathrm{P}}$ performance could be a better way for understanding and identifying the real causes of performance degradation and thereby necessary actions can be taken promptly for improving it. There is no standard method to evaluate the performance of $G_{\mathrm{P}}$ as
Table 5 Management coefficient scores for different medical devices under safe condition [15, 25]

\begin{tabular}{llllll}
\hline Medical Equipment & Equipment Types & $E_{F}$ & $E_{R}$ & $E_{P M}$ & $E_{C E M C}$ \\
\hline Cardiac Defibrillator & Life Recovery & 10 & 1 & 5 & 16 \\
Intensive Care Unit Ventilator & Life Support & 9 & 1 & 5 & 15 \\
Anesthesia work station & Surgical and Intensive Care & 8 & 1 & 5 & 14 \\
Infusion pumps & Life Support & 7 & 1 & 5 & 13 \\
Biochemistry analyzer & Analytical Laboratory Device & 6 & 1 & 5 & 12 \\
\hline
\end{tabular}


Table 6 Management coefficient scores for different medical devices at unsafe condition $[15$, 25]

\begin{tabular}{llllll}
\hline Medical Equipment & Equipment Types & $E_{F}$ & $E_{R}$ & $E_{P M}$ & $E_{C E M C}$ \\
\hline Cardiac Defibrillator & Life Recovery Therapeutic & 10 & 5 & 5 & 20 \\
Intensive Care Unit Ventilator & Life Support & 9 & 5 & 5 & 19 \\
Anesthesia workstation & Surgical and Intensive Care & 8 & 5 & 5 & 18 \\
Infusion pumps. & Life Support & 7 & 5 & 5 & 17 \\
Biochemistry analyzer & Analytical Laboratory Device & 6 & 5 & 5 & 16 \\
\hline
\end{tabular}

reported so far [11]. Different engineering methodologies are normally used in different countries [21]. The conventional methodology is commonly used in lower-middle-income countries like Bangladesh, in which the staffs' positions, as well as their numbers, are selected without taking into account of workload. That is, not on the basis of the number of medical and surgical equipment and the amount of medical equipment technology ability of different hospitals. As a result, the performance of $G_{\mathrm{P}}$ is not at a satisfying level. It is well established that the performance of $G_{\mathrm{P}}$ is strongly dependent on the number of FETs. So, if a CED is formed with insufficient staffs the performance of $G_{\mathrm{P}}$ will be lost; on the other hand; overstaffing will be very much expensive and time-consuming.

In this study analytical method is used that is based on the data related to the performance of $G_{\mathrm{p}}$. In this method, skilled number staffs have been selected based-on workload of a hospital such as a number and complexity level of medical \& surgical equipment as well as the intensity of medical equipment technology ability. In this method, data collection is convenient, fast, cost-effective, and suitable for need-based customization. For the calculation of skilled staffs in a CED, it is required to collect data for the proposed analytical method. We have presented necessary data that are collected from three hospitals including high-, upper- and lower-middleincome countries as an example. The list of hospitals along with data is shown in Table 7.

Based on the standard data, it is required to determine the FTEs on the basis of the workload of 1000 beds hospital for standardizing the performance of $G_{\mathrm{P}}$. It is to be noted that the variable parameters of $G_{\mathrm{P}}$ depend on the skilled number of staffs in CED.

\subsubsection{Calculation of staffs in CED}

There are no widely accepted methods to determine an appropriate number of skilled staff for a CED. Using data collected from 253 hospitals, B. Wangin [29] suggested that 2.5 biomedical FTEs may be employed per 100 beds hospital. An FTE (full-time employee) is defined as a worker who works8 hours/day $(40 \mathrm{~h} /$ week $\times 52$ weeks/year $=2080 \mathrm{~h} /$ year $)$. But, $2080 \mathrm{~h}$ in a year is the absolute calculation without considering holidays, vacation time, sick time, and so on. Taking into account these, the working hours for an FTE per year could be as low as $1680 \mathrm{~h}$. So, additional FTEs are required for bearing a 400 -h workload in the whole year and it is $23 \%$ of $1680 \mathrm{~h}$, that is, the total number of employees will be 1.24 FTEs. In this study, FTE $=1.0$ means full-time employee; while FTE = 0.5 is half-time/part-time employee.

The required number of staff for a CED cannot be estimated by the straight forward way [9, 24-29]. It differs from one organization to another organization and depends on several factors but not limited to: Type and location of the healthcare institute, Size - the number of beds and number of inventories, Type of medical equipment, Availability of resources - training, service manuals, spare parts, vendors, budget - operation and maintenance, etc. Using the above analysis the numbers of FTEs with technology weighted factors of 1000-1200 beds general hospital are calculated and shown in Table 8 .

From Table 4, it is found that the effective number of FTEs for $1000-1200$ beds hospital is about 54 . So, the total number of FTEs is about $67(1.24 \times 54)$ considering holidays and other leaves. According to $[9,24,29]$, the maximum and minimum numbers of FTEs for 1000-1200 beds hospital are about 67

Table 7 Standard data collected from the hospitals of high-, upper- and lower-middle-income countries [9, 27-28]

\begin{tabular}{|c|c|c|c|c|c|c|c|c|}
\hline SL\# & Hospital name & Beds & Country & *MEUD & Doctor & Nurses & $\begin{array}{c}\mathrm{CE} \\
/ \\
\mathrm{BME}\end{array}$ & ${ }^{+}$FTEs \\
\hline 1 & ASO Iizuka Hospital & 1116 & Japan & 14 & 279 & 1104 & 63 & 63 \\
\hline 2 & General Hospital Kulalaumpur & 600 & Malaysia & 10 & 200 & 500 & 39 & 39 \\
\hline 3 & BIRDEM General Hospital & 800 & Bangladesh & 12 & 365 & 650 & 25 & 25 \\
\hline
\end{tabular}

* MEUD/ CD: Medical equipment user department/Clinical department

${ }^{+}$FTEs $=$Full-time employees 
Table 8 Weight of FTEs corresponding to the number of medical devices/workload for the 1000-1200 beds general hospital [24, 29]

\begin{tabular}{|c|c|c|c|c|c|}
\hline Sl. No. & Patient delivery locations & No. of Beds/ Station & $\begin{array}{l}\text { No. of medical } \\
\text { devices/ workload }\end{array}$ & $\begin{array}{l}\text { Price of medical } \\
\text { devices in } \mathrm{M} \$\end{array}$ & Weight of FTEs \\
\hline 1 & Critical Care Beds ICU-CCU & 40 & 200 & 7.5 & 6 \\
\hline 2 & Cardiovascular Surgery (Perfusion) & 3 & 100 & 4.75 & 3.8 \\
\hline 3 & Haemodialysis Center & 20 & 80 & 2.5 & 2 \\
\hline 4 & Hyperbaric Oxygen Therapy & 20 & 30 & 2.25 & 1.8 \\
\hline 5 & Operation Room & 10 & 200 & 3.5 & 2.8 \\
\hline 6 & Endoscopy Lab & 4 & 40 & 3 & 2.4 \\
\hline 7 & Catheterization Laboratory & 2 & 60 & 4 & 3.2 \\
\hline 8 & Neonatal ICU & 10 & 100 & 2.5 & 2 \\
\hline 9 & Clinical Pathology Biochemistry and Blood Bank & 5 & 400 & 5.25 & 4.2 \\
\hline 10 & Ultrasound, Doppler Echo Lab & 2 & 20 & 1.75 & 1.4 \\
\hline 11 & CT, MRI, Digital X-ray Mammography suits & 5 & 200 & 5.5 & 4.4 \\
\hline 12 & Urology Lab & 2 & 75 & 2.75 & 2.2 \\
\hline 13 & Dental lab & 2 & 100 & 2.25 & 1.8 \\
\hline 14 & $\begin{array}{l}\text { Supporting departments such as medical gases, } \\
\text { waste management, sterilization, radiotherapy, etc. }\end{array}$ & 6 & 400 & 20 & 16 \\
\hline \multicolumn{2}{|c|}{ Total numbers for 13 different CEDs. } & 138 & 2005 & 67.25 & 53.8 \\
\hline
\end{tabular}

and 32, respectively, and that depends on the number of clinical departments as well as the number of complexity of clinical equipment that has been used for patient care. It is found in [7] that the ratio among skilled staffs for quality CED model can be arranged as CE:CET:BMET $=1: 2: 3$. So, the FTEs ratio will be CE:CET:BMET = 54:108:162 for 1000-1200 beds hospital. This rationalized means for $1000-1200$ beds in modern hospitals with 14 different clinical departments to ensure $24 \mathrm{~h}$ support to the patient by applying clinical engineering management methodologies. These FTEs are considered for $24 \mathrm{~h}$ services, so for each shift with $8 \mathrm{~h}$ duration, it will be divided by 3 , which is also supported by WHO reports [8-9]. So, the ratio of FTEs per shift among CE, CET, and BMET can be presented as CE: CET: BMET = 18: 36: 54 . The standard manpower setup of a CED for providing $24 \mathrm{~h}$ services can be represented in Fig. 3 on the basis of $[8-9,21,29]$. This rationalized means for 1000-1200 beds in modern hospitals with 14 different clinical departments to ensure $24 \mathrm{~h}$ support to the patient by applying clinical engineering management methodologies. These FTEs are considered for $24 \mathrm{~h}$ services, so for each shift with $8 \mathrm{~h}$ duration, it will be divided by 3 , which is also supported by WHO reports [9]. So, the ratio of FTEs per shift among CE, CET, and BMET can be presented as CE: CET: BMET = 18:36:54. The standard manpower setup of a CED for providing $24 \mathrm{~h}$ services can be represented in Fig. 3 on the basis of [8-9, 21].

Here, DCE (Director clinical engineering), Sr. CE (Senior Clinical Engineer), ACE (Assistant Clinical Engineer), CET (Clinical Engineering Technologist), and BMET (Biomedical Equipment Technician). The numbers of staff are indicated by the respective numerical value $[8-9,11]$. The constant and variable parameters of $G$ p are shown in Table 9.

Figure 3 shows five distinct positions of staff for a CED and these are constant parameters and the number of staff of the respective positions is the variable parameters. The constant and variable parameters are listed in Table 9. These parameters are very much important for standardizing the performance of $G_{\mathrm{P}}$. The score of the parameters depends on the workload such as the complexity of medical \& surgical equipment and intensity of medical equipment technology and other
Fig. 3 Proposed staff set up for the standard CED of in 1000 1500 beds hospital

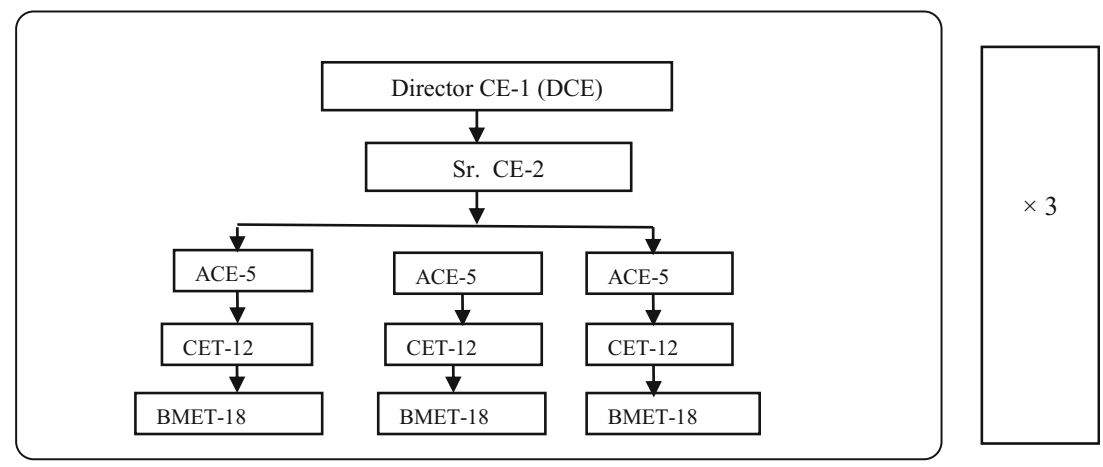


Table 9 List of constant and variable parameters of $G_{\mathrm{P}}$

\begin{tabular}{|c|c|c|c|c|c|}
\hline \multicolumn{2}{|c|}{ Constant parameters } & \multirow{2}{*}{$\begin{array}{l}\text { Unit } \\
\text { No. of equipment/year }\end{array}$} & \multicolumn{3}{|c|}{ Variable parameters } \\
\hline$g_{1}$ & Performance evaluation test $\&$ auditing & & $z_{1}$ & No. of FTEs for $g_{i}$ & year \\
\hline$g_{2}$ & Preventive maintenance test & & $z_{2}$ & & \\
\hline$g_{3}$ & Inspection and acceptance test & & $z_{2}$ & & \\
\hline$g_{4}$ & Safe operation test & & $z_{4}$ & & \\
\hline$g_{5}$ & In-service education \& training & & $z_{5}$ & & \\
\hline
\end{tabular}

activities of a hospital. The list of variable parameters along with their weights for 13 different medical equipment users' department (MEUD) of 1000 beds hospital is shown in Table 10.

\subsubsection{Determination of standard performance parameters of $A_{\mathrm{P}}$}

The performance of $A_{\mathrm{P}}$ depends on the staff's educational qualification as well as their skills level on PCTMS. Here, we have assumed that all the staff of CED are skilled in their respective fields. So, the skill level of staff and the number of staff can be considered as constant and variable parameters, respectively. The constant and variable parameters of $A_{\mathrm{P}}$ are listed in Table 11.

The workload of CED is determined by the number of MEUDs rather than the number of beds of a hospital. So, the number of FTEs varies from hospital to hospital depending on the workload, that is, on the complexity of medical equipment and its technology level. Table 12 shows 14 MEUDs of 12 different hospitals having 1000 beds each. The data shown in Table 12 are collected from the hospitals of higher-, upper-, and lower-middle-income countries [8, 24, 28]. The number of FTEs belongs to a CED is classified by five posts such as DCE, Sr. CE, ACE, CET, and BMET. These are considered as constant parameters but their numbers are different and can be considered as variable parameters of $A_{\mathrm{P}}$. The data shown in Table 12 are collected for the care number of 14 but the number of medical equipment, the complexity of the equipment, and the technology level are different. These data are used to determine the FTEs for different CEDs of 12 hospitals basedon total workload [11].

We present the technological weights of variable parameters with respect to FETs of 12 different 1000 beds hospitals in Table 13 as an example. The weights of variable parameters for 14 different MEUDs depend on the total number of FTEs, which vary from hospital to hospital as shown in Table 12. The weights of the parameters depend on the FETs as clearly indicated in Table 13.

The number of skilled staff for standardizing the CED of different clinical departments is calculated by the number of FETs.

\subsubsection{Determination of standard performance parameters of $A_{F}$}

The overall performance of the proposed system related to the $A_{F}$ (feedback factor), that is, on the prompt/on-time response of the regulatory body, HCED. Basically, the selection of the parameters of $A_{\mathrm{F}}$ depends on the structure of HCED. Here we
Table 10 List of variables parameters of $G_{\mathrm{P}}$ along with their respective weights of 13 different MEUDs for 1000 beds hospital $[11,22,29]$

\begin{tabular}{|c|c|c|c|c|c|c|c|}
\hline \multirow[t]{2}{*}{ Data sample } & \multirow[t]{2}{*}{ Name of MEUD } & \multirow[t]{2}{*}{ FTEs } & \multicolumn{5}{|c|}{ Variable parameters of $G_{P}$} \\
\hline & & & $\mathrm{z}_{1}$ & $\mathrm{z}_{2}$ & $\mathrm{z}_{3}$ & $\mathrm{z}_{4}$ & $\mathrm{z}_{5}$ \\
\hline 1 & Critical Care Beds ICU-CCU & 36 & 1 & 2 & 3 & 12 & 18 \\
\hline 2 & Cardiovascular Surgery (Perfusion) & 22.8 & 1 & 1 & 2 & 8 & 10.5 \\
\hline 3 & Haemodialysis Center & 12 & 0 & 1 & 1 & 4 & 6 \\
\hline 4 & Hyperbaric Oxygen Therapy & 10.8 & 0 & 1 & 2 & 4 & 5.8 \\
\hline 5 & Operation Room & 16.8 & 1 & 1 & 2 & 6 & 6.6 \\
\hline 6 & Endoscopy Lab & 14.4 & 0 & 1 & 1 & 7 & 5.5 \\
\hline 7 & Catheterization Laboratory & 19.2 & 1 & 1 & 1 & 6 & 11.2 \\
\hline 8 & Neonatal ICU & 12 & 0 & 1 & 1 & 4 & 6 \\
\hline 9 & Clinical Pathology Biochemistry and Blood Bank & 25.2 & 1 & 2 & 2 & 6 & 12.5 \\
\hline 10 & Ultrasound and Doppler Echo Lab & 8.4 & 0 & 0 & 1 & 4 & 3.4 \\
\hline 11 & CT, MRI, Digital X-ray Mammography suits & 26.4 & 1 & 2 & 2 & 7 & 14.6 \\
\hline 12 & Urology Lab & 12 & 0 & 1 & 1 & 5 & 5 \\
\hline 13 & Dental lab & 10.8 & 0 & 0 & 1 & 4 & 5.8 \\
\hline
\end{tabular}


Table 11 List of constant and variable parameters of $A_{\mathrm{P}}$

\begin{tabular}{|c|c|c|c|c|c|c|}
\hline \multirow{2}{*}{$\begin{array}{l}\text { Staff's } \\
\text { position }\end{array}$} & \multicolumn{2}{|c|}{ Constant parameters } & \multirow{2}{*}{$\begin{array}{l}\text { Unit } \\
\text { Year }\end{array}$} & \multicolumn{2}{|c|}{ Variable parameters } & \multirow{2}{*}{$\begin{array}{l}\text { Unit } \\
\text { No./year }\end{array}$} \\
\hline & $b_{1}$ & Basic education, training/postgraduate & & $y_{1}$ & \multirow{5}{*}{$\begin{array}{l}\text { Number of a } \\
\text { full-time employ- } \\
\text { ee (FTEs) }\end{array}$} & \\
\hline Sr. CE & $b_{2}$ & certificate, and service lengths & & $y_{2}$ & & \\
\hline $\mathrm{ACE}$ & $b_{3}$ & & & $y_{3}$ & & \\
\hline CET & $b_{4}$ & & & $y_{4}$ & & \\
\hline BMET & $b_{5}$ & & & $y_{5}$ & & \\
\hline
\end{tabular}

have proposed the following parameters as an example: chief clinical engineer (CCE), director clinical engineering (DCE), clinical engineering manager (CEM), and senior clinical engineer (Sr. CE). The constant parameters of $A_{F}$ are determined by the skill level of four higher posts and variable parameters are by their numbers. Since the $A_{\mathrm{F}}$ regulates the performance of PCTMS for entire countries and $A_{\mathrm{P}}$ works in a hospital, the variable parameters, that is, the number of staff of HCED is dependent on the number of CEDs of all hospitals under healthcare delivery system in a country. Based on this concept, the constant and variable parameters of $A_{\mathrm{F}}$ are listed in Table 14 [11, 29].

The weights of variable parameters of $A_{\mathrm{F}}$ are shown in Table 15 with respect to the number of FTEs/shift for different categories of hospitals.

\subsection{Standardizing the performance of $G_{\mathrm{P}}, A_{\mathrm{P}}$, and $A_{\mathrm{F}}$}

The goal of this study is to develop a mathematical model to evaluate the QPC taking into account CEA in PCDS. According to the discussion of preceding sections patient care depends on many factors. Considering the variable parameters independent a statistical tool can be used that is capable of relating multiple independent variables to a dependent variable. This facilitates to predict standard performances of PCTMS, CED, and HCED, which are defined as $G_{\mathrm{P}}, A_{\mathrm{P}}$, and $A_{\mathrm{F}}$, respectively, in previous sections. The lists of constant and variable parameters related to the standard performance of $G_{\mathrm{P}}$, $A_{\mathrm{P}}$, and $A_{\mathrm{F}}$ are mentioned in Tables 9, 11, and 14. Since the variable parameters are independent and human engineering errors are involved with the parameters of $G_{\mathrm{P}}, A_{\mathrm{P}}$, and $A_{\mathrm{F}}$ multiple linear regression analysis [10, 30, 31-32] can be used for standardizing the performance of PCTMS, CED, and HCED.

\subsubsection{Modeling of $G_{\mathrm{P}}, A_{\mathrm{P}}$, and $A_{\mathrm{F}}$ using multiple linear regression method}

The standard performance of $G_{\mathrm{P}}$ can be expressed by the following multiple linear regression equation of Eq. (4).

$\hat{G}_{p}=g_{0}+g_{1} z_{1}+g_{2} z_{2}+g_{3} z_{3}+g_{4} z_{4}+g_{5} z_{5}$

where $\hat{G}_{P}$ is the expected/desired performance, and $z_{1}$ to $z_{5}$ are

Table 12 List of MEUDs of different 12 hospitals and each hospital consists of 1000 beds

\begin{tabular}{|c|c|c|c|c|c|c|c|c|c|c|c|c|c|}
\hline SL\# & Name of MEUD & $\mathrm{H}_{1}$ & $\mathrm{H}_{2}$ & $\mathrm{H}_{3}$ & $\mathrm{H}_{4}$ & $\mathrm{H}_{5}$ & $\mathrm{H}_{6}$ & $\mathrm{H}_{7}$ & $\mathrm{H}_{8}$ & $\mathrm{H}_{9}$ & $\mathrm{H}_{10}$ & $\mathrm{H}_{11}$ & $\mathrm{H}_{12}$ \\
\hline 1 & Critical Care Beds ICU-CCU & 40 & 16 & 12 & 8 & 8 & 14 & 20 & 6 & 9 & 16 & 20 & 24 \\
\hline 2 & Cardiovascular Surgery (Perfusion) & 3 & 1 & 1 & 0 & 1 & 0 & 0 & 0 & 1 & 1 & 1 & 1 \\
\hline 3 & Haemodialysis Center & 20 & 20 & 10 & 8 & 4 & 4 & 4 & 4 & 4 & 4 & 4 & 10 \\
\hline 4 & Hyperbaric Oxygen Therapy & 20 & 10 & 3 & 3 & 3 & 3 & 3 & 2 & 4 & 2 & 3 & 5 \\
\hline 5 & Operation Room & 10 & 12 & 5 & 5 & 5 & 5 & 5 & 5 & 5 & 3 & 4 & 6 \\
\hline 6 & Endoscopy Lab & 4 & 4 & 2 & 2 & 2 & 1 & 1 & 1 & 1 & 1 & 2 & 2 \\
\hline 7 & Catheterization Laboratory & 2 & 1 & 1 & 1 & 1 & 0 & 0 & 0 & 1 & 0 & 1 & 2 \\
\hline 8 & Neonatal ICU & 10 & 8 & 4 & 2 & 2 & 2 & 2 & 2 & 2 & 2 & 2 & 2 \\
\hline 9 & Clinical Pathology Biochemistry and Blood Bank & 5 & 4 & 2 & 3 & 2 & 2 & 2 & 2 & 2 & 2 & 3 & 3 \\
\hline 10 & Ultrasound and Doppler Echo Lab & 10 & 6 & 4 & 4 & 4 & 4 & 4 & 4 & 4 & 3 & 5 & 6 \\
\hline 11 & CT, MRI, Digital X-ray and Mammography suits & 5 & 4 & 3 & 3 & 3 & 3 & 3 & 3 & 3 & 3 & 3 & 3 \\
\hline 12 & Urology Lab & 2 & 2 & 1 & 1 & 1 & 1 & 1 & 1 & 2 & 1 & 1 & 1 \\
\hline 13 & Dental lab & 5 & 1 & 1 & 1 & 1 & 1 & 1 & 1 & 1 & 1 & 1 & 1 \\
\hline 14 & Other Supporting department & 2 & 2 & 2 & 2 & 2 & 2 & 2 & 2 & 2 & 2 & 2 & 2 \\
\hline \multicolumn{2}{|c|}{ Total workload } & 138 & 90 & 50 & 42 & 38 & 41 & 47 & 32 & 31 & 41 & 51 & 67 \\
\hline \multicolumn{2}{|c|}{ No. of FETs } & 36 & 23.48 & 14.60 & 13.04 & 10.95 & 9.91 & 10.69 & 12.26 & 8.34 & 8.08 & 10.43 & 17.47 \\
\hline
\end{tabular}


Table 13 List of variable parameters of $A_{\mathrm{P}}$ along with their technological weights with respect to FTEs for12 different 1000 beds hospitals $[9,11,29]$

\begin{tabular}{|c|c|c|c|c|c|}
\hline \multirow[t]{2}{*}{ No. of FTEs } & \multicolumn{5}{|c|}{ Variable parameters } \\
\hline & $\mathrm{y}_{1}$ & $\mathrm{y}_{2}$ & $\mathrm{y}_{3}$ & $\mathrm{y}_{4}$ & $\mathrm{y}_{5}$ \\
\hline 36.00 & 1 & 2 & 3 & 12 & 18 \\
\hline 23.48 & 0 & 0 & 1 & 2 & 3 \\
\hline 14.60 & 0 & 1 & 0 & 2 & 4 \\
\hline 13.04 & 0 & 1 & 1 & 3 & 6 \\
\hline 10.95 & 0 & 0 & 1 & 4 & 8 \\
\hline 9.91 & 0 & 1 & 1 & 5 & 9 \\
\hline 10.69 & 1 & 1 & 3 & 4 & 10 \\
\hline 12.26 & 1 & 2 & 3 & 8 & 12 \\
\hline 8.34 & 1 & 3 & 6 & 8 & 14 \\
\hline 8.08 & 1 & 2 & 8 & 12 & 14 \\
\hline 10.43 & 1 & 3 & 6 & 12 & 18 \\
\hline 17.47 & 1 & 2 & 7 & 16 & 20 \\
\hline
\end{tabular}

the five distinct independent variables. The number of these variables depends on the number of beds in a hospital. For 300 to 1200 beds hospital, the maximum number is 5 . If the number of beds is below 300 , the number of these variables will be less than 5 . Here, $\mathrm{g}_{0}$ is the initial performance of $G_{\mathrm{P}}$ (if any) and $g_{1}$ to $g_{5}$ are the regression coefficients. The estimated/ actual performance of $G_{P}$ can be expressed by Eq. (5).

$G_{p}=g_{0}+g_{1} z_{1}+g_{2} z_{2}+\ldots+g_{k} z_{k}$

The error or performance loss can be expressed by Eq. (6).

$e=\hat{G}_{P}-G_{p}$

In the case of $n$ observations with $k+1$ variable, the error of performance estimation is given in Eq. (7).

$e_{i}=\hat{G}_{P i}-g_{0}-\sum_{j=1}^{k} g_{j} z_{i, j}, \quad i=1,2, \ldots, n$

The sum of the square of error performances can be expressed by Eq. (8).

$S=\sum_{i=1}^{n} e_{i}^{2}=\sum_{i=1}^{n}\left(\hat{G}_{P i}-g_{0}-\sum_{j=1}^{k} g_{j} z_{i, j}\right)^{2}$
The Eq. (8) is differentiated with respect to the model parameters $g_{0}, g_{1}, \ldots, g_{\mathrm{k}}$ and then applying the principle of least square, following normal equations are derived:

$$
\begin{aligned}
& n g_{0}+g_{1} \sum_{i=1}^{n} z_{i, 1}+g_{2} \sum_{i=1}^{n} z_{i, 2}+\ldots+g_{k} \sum_{i=1}^{n} z_{i, k}=\sum_{i=1}^{n} \hat{G}_{P i} \\
& g_{0} \sum_{i=1}^{n} z_{i, 1}+g_{1} \sum_{i=1}^{n} z_{i, 1}^{2}+g_{2} \sum_{i=1}^{n} z_{i, 1} z_{i, 2}+\ldots+g_{k} \sum_{i=1}^{n} z_{i, 1} z_{i, k} \\
& =\sum_{i=1}^{n} z_{i, 1} \hat{G}_{P i} \\
& g_{0} \sum_{i=1}^{n} z_{i, k}+g_{1} \sum_{i=1}^{n} z_{i, k} z_{i, 1}+g_{2} \sum_{i=1}^{n} z_{i, k} z_{i, 2}+\ldots+g_{k} \sum_{i=1}^{n} z_{i, k}^{2} \\
& \quad=\sum_{i=1}^{n} z_{i, k} \hat{G}_{P i}
\end{aligned}
$$

With the combination of Eqs. (9-11) and using the data set presented in Tables 9 and 10, the values of regression coefficients $g_{0}, g_{1} \ldots$, and $g_{\mathrm{k}}$ are determined. Finally, by substituting the values of these coefficients in Eqs. (9-11), the performance equation of $G_{\mathrm{p}}$ is determined and can be represented by

$$
\begin{aligned}
G_{P}= & 14-32.928 z_{1}-3.038 z_{2}+16.7 z_{3}+6.92 z_{4} \\
& +1.71 z_{5}
\end{aligned}
$$

Similarly, we can determine the standard performance equations of $A_{\mathrm{P}}$ and $A_{\mathrm{F}}$ using the data presented in Tables 11 and 13, and Tables 14 and 15, respectively. The standard performance equations of $A_{\mathrm{P}}$ and $A_{\mathrm{F}}$ can be expressed by

$$
\begin{aligned}
A_{P}= & 16-47.57 y_{1}-2.027 y_{2}+3.822 y_{3}-10.937 y_{4} \\
& +13.95 y_{5} \\
A_{F}= & 20+33.70 x_{1}-5.02 x_{2}+0.19 x_{3}+4.41 x_{4}
\end{aligned}
$$

\begin{tabular}{|c|c|c|c|c|}
\hline HCED & Constant parameters & \multirow{2}{*}{$\begin{array}{c}\text { Unit } \\
\text { Year }\end{array}$} & \multirow{2}{*}{$\begin{array}{l}\begin{array}{l}\text { Variable } \\
\text { parameter }\end{array} \\
x_{1}\end{array}$} & \multirow{2}{*}{$\begin{array}{l}\text { Unit } \\
\text { No./year }\end{array}$} \\
\hline $\mathrm{CCE}$ & Engineering qualification and managerial skilled & & & \\
\hline DCE & $a_{2} \quad$ on PCTMS & & $x_{2}$ & \\
\hline CEM & $a_{3}$ & & $x_{3}$ & \\
\hline Sr. CE & $a_{4}$ & & $x_{4}$ & \\
\hline
\end{tabular}

The values of goodness-of-fit i.e. $R^{2}$ for deriving the standard performance equations of $G_{\mathrm{P}}, A_{\mathrm{P}}$, and $A_{\mathrm{F}}$ are found to be $89.68 \%, 88.08 \%$, and $97.47 \%$, respectively. It is well established that the minimum acceptable range of $R^{2}$ is $80 \%$ in any statistical analysis.
Table 14 List of constant and variable parameters of $A_{\mathrm{F}}$ 
Table 15 Weights of variable parameters of $A_{\mathrm{F}}$ with respect to the number of beds in different hospitals [11, 29]

\begin{tabular}{llllllll}
\hline SL\# & No. of hospital & No. of beds & No. of FTEs for 8 h. (one shift) & \multicolumn{3}{c}{ Variable parameters of $A_{F}$} \\
\cline { 5 - 7 } & & & & $x_{1}$ & $x_{2}$ & $x_{3}$ & $x_{4}$ \\
\hline 1 & 12 & $1000-1200$ & 188.5 & 1 & 8 & 12 & 18 \\
2 & 20 & $500-600$ & 171.25 & 1 & 6 & 8 & 12 \\
3 & 15 & $400-450$ & 155 & 1 & 4 & 6 & 10 \\
4 & 10 & $300-375$ & 149.5 & 1 & 3 & 4 & 12 \\
5 & 20 & $250-270$ & 139 & 1 & 2 & 8 & 16 \\
6 & 29 & $100-200$ & 128.75 & 1 & 2 & 8 & 10 \\
7 & 191 & $50-80$ & 275 & 1 & 2 & 15 & 18 \\
8 & 280 & $31-45$ & 375 & 1 & 1 & 7 & 18 \\
\hline
\end{tabular}

\section{Evaluation of QPC by the proposed model}

After having the standard performance equations of $G_{\mathrm{P}}, A_{\mathrm{P}}$, and $A_{\mathrm{F}}$ the proposed model is applied to reveal the present status of QPC for different countries. In order to do so, the output performance of PDCS, that is, the quantitative amount of $C_{\mathrm{P}}$ are evaluated for 18 different countries (including high-, upper- and lower-middle-income countries) combining Eq. (1) and Eqs. (12-14). It is noted that the results presented here are evaluated by setting the on-time response indicator $A_{\mathrm{F}}=1$ for each country for convenient evaluation. The results are listed in Table 16 and graphically presented in Fig. 4.

As seen in Fig. 4 and Table 16 the performance of PCDS is found to be $84.69 \%$ for Japan and it is the highest value among the countries studied here. The results obtained in the present study demonstrate that the performance of PCDS is found more than $45 \%$ for the countries like Slovene (SVN), Belgium (BEL) Ireland (IRL), etc. On the other hand, it is found to be very poor for countries like Finland (FIN), Israel (ISR), Austria (AUS), etc. The results presented here also demonstrate that the density of clinical engineer as well as the adaptation of CEA in PCTMS is the main factor to improve QPC for a particular country. In some countries, the performance of PCDS is found to be at a very unsatisfactory level, which may be due to the fact that they did not introduce CEA in their HCDS $[8-9,11]$. This implies that the model is able to explain the QPC of the countries where CEA has been introduced or not. Thus, the proposed model is universal and any country/hospital can easily evaluate the present status of QPC and then take necessary action accordingly. Our model
Table 16 Present status of QPC for 18 different countries (including high-, upper- and lower-middle-income)

\begin{tabular}{|c|c|c|c|c|c|c|c|}
\hline $\begin{array}{l}\text { Sl. } \\
\text { No. }\end{array}$ & Country & $A_{P}$ & $G_{P}$ & $\begin{array}{l}\text { On-time } \\
\text { Response } \\
\text { lind., } A_{F}\end{array}$ & $\begin{array}{l}\text { System } \\
\text { Transfer } \\
\text { Function, } H\end{array}$ & $\begin{array}{l}\text { Expected } \\
\text { Performance, } \\
R_{P}=(\%)\end{array}$ & $\begin{array}{l}\text { Actual } \\
\text { Performance, } \\
C_{P}(\%)\end{array}$ \\
\hline 1 & Japan & 1.58 & 3.5 & 1 & 0.846861 & 100 & 84.69 \\
\hline 2 & Slovene & 0.84 & 1.35 & 1 & 0.531396 & 100 & 53.14 \\
\hline 3 & Belgium & 0.87 & 1.25 & 1 & 0.520958 & 100 & 52.10 \\
\hline 4 & Ireland & 0.7 & 1.21 & 1 & 0.458581 & 100 & 45.86 \\
\hline 5 & Kiribati & 0.27 & 2.93 & 1 & 0.441684 & 100 & 44.17 \\
\hline 6 & Malysia & 0.82 & 0.84 & 1 & 0.407864 & 100 & 40.79 \\
\hline 7 & Panama & 0.83 & 0.74 & 1 & 0.380498 & 100 & 38.05 \\
\hline 8 & Mongolia & 0.81 & 0.74 & 1 & 0.374766 & 100 & 37.48 \\
\hline 9 & Finlnand & 2.73 & 0.09 & 1 & 0.197239 & 100 & 19.72 \\
\hline 10 & Iserial & 2.48 & 0.09 & 1 & 0.182472 & 100 & 18.25 \\
\hline 11 & Romania & 0.64 & 0.3 & 1 & 0.161074 & 100 & 16.11 \\
\hline 12 & Jordan & 0.67 & 0.16 & 1 & 0.096821 & 100 & 9.68 \\
\hline 13 & Austria & 0.13 & 0.43 & 1 & 0.052941 & 100 & 5.29 \\
\hline 14 & India & 0.34 & 0.12 & 1 & 0.039201 & 100 & 3.92 \\
\hline 15 & $\begin{array}{l}\text { South } \\
\text { Africa }\end{array}$ & 0.06 & 0.34 & 1 & 0.019992 & 100 & 2.00 \\
\hline 16 & Maldives & 0.03 & 0.037 & 1 & 0.001109 & 100 & 0.11 \\
\hline 17 & Bhutan & 0.08 & 0.047 & 1 & 0.003746 & 100 & 0.37 \\
\hline 18 & Pakistan & 0.02 & 0.1 & 1 & 0.001996 & 100 & 0.20 \\
\hline
\end{tabular}


Fig. 4 Present status of QPC, that is, $C_{\mathrm{P}}$ for 18 different countries

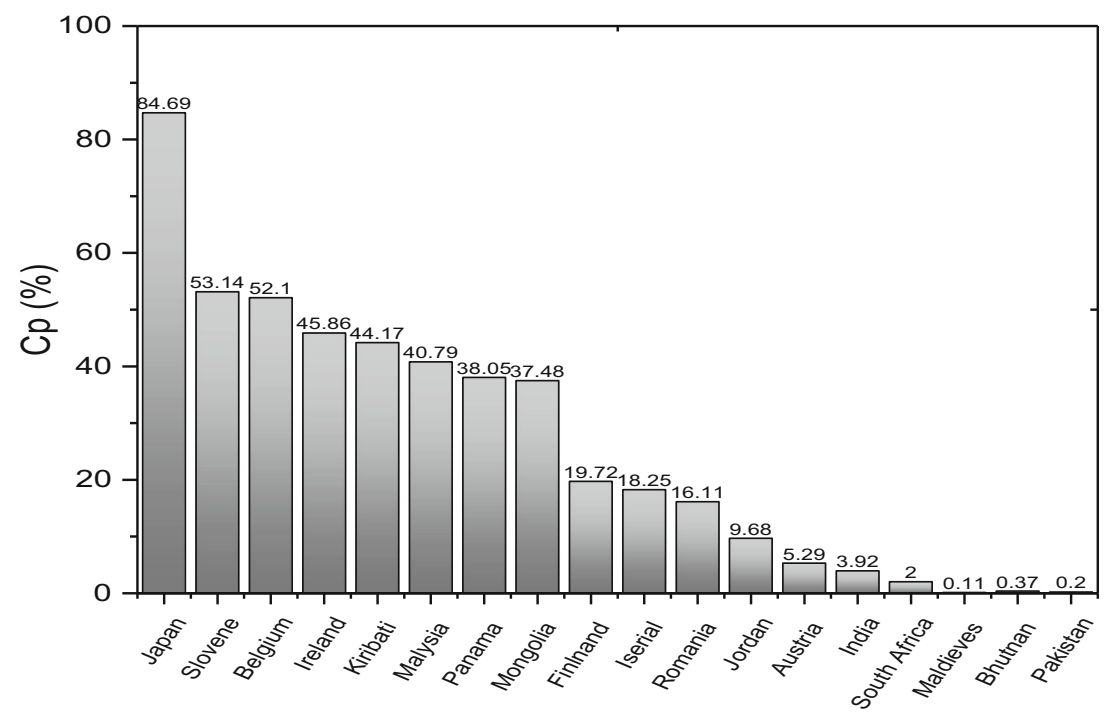

also helps to identify which module/subsection needs to improve for the overall performance improvement.

\section{Conclusions}

In this article, we for the first time develop a mathematical model for quantitative evaluation of QPC by introducing CEA in PCDS of a hospital/clinic/health institution. It is well established that patient satisfaction depends on quality-care and cost-effective-care that can be achieved by on-time interfacing of safe and functional medical devices to the patients. Without introducing CEA in PCDS it is impossible to interface safe and functional medical devices timely and safely. This is clearly identified from the analysis of the data collected from different hospitals of high, upper-middle, and lower-middleincome countries of the world. Although the patient's satisfaction level has been increased by some high-income countries like Japan, Belgium, Slovene, etc., by introducing CEA in their PCDS, there is no mathematical tool to evaluate QPC quantitatively. Here we have presented a mathematical model to evaluate the QPC quantitatively by introducing CEA in PCDS following the analogy of control theory. Different subsections of the models and their correlation with PCDS, FTEs required in a CED and their dependency with the number of beds of a hospital and MEUDs are also clarified. Furthermore, the characteristics of model parameters are defined and the technological weights of these parameters are proposed based on the standard data collected from different hospitals of the world. The performance equations of the model are standardized using the multiple linear regression method. Finally, the model is applied to reveal the present status of QPC in different 18 countries including high- middle-, and low-income countries. The results obtained from the model indicate that the impact of CEA in
PCDS is very much significant and play a vital role to ensure the QPC of a country. The model can be applied to evaluate the QPC of a hospital or a country and it facilitates identifying which subsections of the model (CED/PCTMS/HCED) need to improve for ensuring QPC. The outcome of this study clearly explains the impact of clinical engineering professionals in PCTMS for ensuring QPC and hence to prevent medical equipment-dependent risk factors, that are related to different adverse events such as patient injuries, unnatural patient's death and reduction of healthcare cost, etc.

Acknowledgments This research work was partially supported by CASR grants, Khulna University of Engineering \& Technology (KUET), Khulna-9203, Bangladesh. We acknowledged this research work to Dept. of BME, KUET, Bangladesh; NEMEMW \& TC, Ministry of Health \& Family Welfare, Dhaka, Bangladesh; Hospitals of Bangladesh for their supports related to data collection that greatly improved the manuscript.

\section{Compliance with ethical standards}

Conflict of interest The authors declare that they have no conflict of interest.

Ethical approval This article does not contain any studies with human participants or animals performed by any of the authors.

Informed consent Informed consent was obtained from all individual participants included in the study.

\section{Appendix 1: Related definitions and terminologies}

(i) Medical Equipment Technology Management: Medical equipment technology management system (METMS) can be defined as the mechanisms for interaction and oversight of the medical equipment used in the diagnosis, treatment, and monitoring of patients. The 
related policies and procedures govern activities from selection and acquisition to incoming inspection and maintenance of medical equipment. The main goal of METMS is to ensure that the equipment used in patient care must be safe, available, accurate, and affordable [35]. Sometimes, METMS is known as the healthcare technology management system (HTMS). HTMS or METMS consists of 10 parameters and patient care is not actively related to 10 parameters [11, 16, 2, 33]. In this study, five core parameters of METMS or HTMS have selected to ensure the quality of patient and the integrated outcome of these five parameters can be defined as patient care technology management system (PCTMS) and this term has been revealed by many publications such as Jim Kline in [34].

(ii) Skilled Clinical Engineer's Approach: Although procedures vary from one field on inquiry to another, they are frequently the same from one to another. The process of skilled clinical engineering method involves making hypotheses, deriving predictions from them as logical consequences, and then carrying out experiments or empirical observations based on those predictions such as quality of CED models and their contributions for appropriate controlling of medical equipment technology outcome to ensure the patient safety [36].

(iii) Clinical Engineering Technologist (CET): "A Clinical Engineering Technologist is defined as a person who practices the operation, maintenance and inspection of clinical life support and control systems, for instance, dialyzers, mechanical ventilators, and artificial heart-lung machines. He or she plays an important role in clinical practices such as cardiac operations, as well as in the education of medical doctors and nurses on the use of medical equipment. Accordingly, he or she is required to obtain medical knowledge and communication ability as a member of a medical practice team in addition to engineering skill" [37].

(iv) Biomedical Equipment Technician (BMET): “A Biomedical Equipment Technician, also referred to as a Biomedical Engineering Technician is typically an electro-mechanical technician who ensures that medical equipment is well-maintained, properly configured, and safely functional. In the hospital or clinical environments, Biomedical Equipment Technicians often work with Clinical Engineers. Biomedical Equipment Technicians install, inspect, maintain, repair, calibrate, modify and design biomedical equipment and support systems to adhere to medical standard guidelines" [38].

(v) Quality Model of CED: The department of Clinical Engineering plays an important role beginning from the procurement process and facilitates effective management of medical devices which are especially used in health care facilities. Additionally, clinical engineering department increases the life cycle of medical devices, optimizes spare parts and technical services' costs of medical devices in order to improve the quality of health care. Accordingly, a quality model of CED can be defined as a set of characteristics such as constant and variable parameters and the relation between them that provide the basis for specifying quality requirements and evaluating the quality of an entity $[39,40]$.

(vi) Healthcare Engineering Directorate (HCED): Healthcare Engineering Directorate (HCED) is a regulatory office that regulates the performance outcomes of PCTMS and enhances the outcomes by applying skilled clinical engineering management methodologies under the healthcare regulatory system for any country. For example, nine directorate offices have been working under the Ministry of Health\& Family Welfare, Government of Bangladesh to ensure the healthcare system [40-43]. Among them, NEMEMW is one of the regulatory authority offices that regulate the medical equipment maintenance management in the public hospitals of Bangladesh [19, 27, 42, 43]. Here HCED is used instead of NEMEMW \& TC to improve the present performance outcomes of medical equipment [44].

\section{References}

1. Powell-Cope G, Nelson AL, Patterson ES, Patient Safety and Quality: An Evidence-Based Handbook for Nurses, Chapter 50, Agency for Healthcare Research and Quality (AHRQ), 2008, US Publications.

2. Six Domains of Health Care Quality. Agency for Healthcare Research and Quality. Available at: https://www.ahrq.gov/ talkingquality/measures/six-domains.html

3. David Y, Jahnke EG. Planning hospital medical technology management. IEEE Engineering in Medicine and Biology Magazine. 2014;23(3):73-9. https://doi.org/10.1109/MEMB.2004.1317985.

4. Clinical engineering (2018). Available at: https://en.wikipedia.org/ wiki/Clinical engineering

5. Hossain MA, Rahman AKM, Rahman MR, Islam MR, and Ahmad $\mathrm{M}$, Role of clinical engineering to reduce patient's risk factors in life support ventilator. 2015 2nd International Conference on Electrical Information and Communication Technologies (EICT), Khulna, 2015, pp. 173-177. DOI: https://doi.org/10.1109/EICT.2015. 7391941.

6. Definition of Patient Safety Patient. Institute of Medicine (IOM), 2016. https://www.theabpm.org/wp-content/themes/abpm-publicsite/docs/Approvedpatientsafetycourse2016.pdf

7. Hossain MA, Ahmad M, Islam MR, Rashid MA. Cost-effective proposal to produce clinical engineering professional to sustain the health care services of developing countries such as Bangladesh International. Journal of Engineering Trends \&Technology. 2015;30(7):351-5. https://doi.org/10.14445/ 22315381/IJETT-V30P265.

8. Stone V. Human resources for medical devices -The role of biomedical engineers. Geneva: World Health Organization; 2017.

9. Igeta H. The Role of Clinical Engineers in JAPAN - A Case of ASO Iizuka Hospital. Denver: AAMI Conference \& Expo; 2015. 
10. Bremer M, 2012. Multiple Linear Regressions. Published in the Journal "Math 261A - Spring 2012".pp -18-36. Link: available at www.mezeylab.cb.bscb.cornell.edu supplement 5 - multiple regressions.

11. Hossain MA, Ahmad M, Islam MR, David Y. Evaluation of Performance Outcomes of Medical Equipment Technology Management and Patient Safety: Skilled Clinical Engineer's Approach. Global Clinical Engineering Journal. 2019;1(2):4-16. https://doi.org/10.31354/globalce.v1i2.46.

12. Grinder S. Patient Safety and Quality Improvement Act of 2005 HHS Guidance Regarding Patient Safety Work Product and Providers' External Obligations, 2016; Agency for Healthcare Research and Quality (AHRQ), pp. 32655-32660.

13. Global Clinical Engineering Day live stream on October 21 st, 2018. Available at the link: https://ive.polyv.cn/watch/244330.

14. Gurses AP, Doyle PA. Medical Devices in the "Wild", 2014. Online publication in AHRQ Patient Safety Network.

15. Sezdi M. Medical Technology Management and Patient Safety. A Roadmap of Biomedical Engineers and Milestones. 2012:183-208. https://doi.org/10.5772/35926.

16. Temple-Bird C. How to Organize a System of Healthcare Technology Management. Healthcare Technology Managementm, 2015. Guide 1, Lewes.

17. Baker GR, et al. The Canadian adverse events study: The incidence of adverse events among hospital patients in Canada. Journal of the Canadian Medical Association. 2004;170(11):1678-86.

18. European Alliance for Medical and Biological Engineering \& Science (EAMBES) (2013). Link: https://esbiomech.org/ affiliated-societies/european-alliance-for-medical-and-biologicalengineering-science-eambes.

19. A Guide to Clinical Engineering Certification - American College of Clinical Engineering, 2017. Enhancing Patient Safety. (2001) The Role of Clinical Engineering, a white paper prepared by the American College of Clinical Engineering. https://accenet.org/ Pages/Default.aspx

20. What is a Regulatory Authority? - Definition from safeopedia. 2018. Link: https://www.safeopedia.com/definition/128/ regulatory-authority-occupational-health-and-safety

21. Joseph D et al, Clinical Engineering Hand Book, 1st Edition. Published in CRC Press, 2004.

22. Health Bulletin, DGHS, Ministry of Health and Family Welfare, Bangladesh, 2016.

23. Directorates and other offices under the Ministry of Health \& Family Welfare, Government of the People's Republic of Bangladesh. Link available at: www.mohfw.gov.bd

24. Clinical Engineering Bank. Staffs for CE service Structures. Link: A web-based data; 2018. https://www.clinicalengineeringbank. com/cefunctions.htm

25. Fennigkoh L, Smith B. Clinical equipment management. JCAHO Plant, Technology \& Safely Management Series. 1989;2:5-14.

26. Williams I. J. et al. (1967) Feedback and control system. Schaum's online Proceedings, series McGraw-Hill.

27. Evans GA (2009) Clinical Engineering Staffing Models. WakeMed Health \& Hospitals, Raleigh. http://www.24x7mag.com/2009/03/ clinical-engineering-staffing-models

28. Wang B. Clinical engineering benchmarking: An analysis of American acute care hospitals. J Clin Eng. 2008;33(1):24-7. https://doi.org/10.1097/01.JCE.0000305843.32684.
29. Iadanza E. IFMBE/Clinical Engineering Division projects for the advancement of the profession of Clinical Engineering. In: Eskola H, Väisänen O, Viik J, Hyttinen J, editors. EMBEC \& NBC 2017. EMBEC 2017, NBC 2017. IFMBE Proceedings, vol. 65. Singapore: Springer; 2018.

30. Hossain MA, Ahmad M, Islam MR, Hossain MD, Rahman AKM, Islam S, et al. Clinical engineering and healthcare delivery performance measurement: A basic model of clinical engineering department for 250-bed hospital in Bangladesh. Bangladesh: Proceeding in 2016 International Conference on Medical Engineering, Health Informatics, and Technology (MediTec); 2016. p. 1-5. https://doi. org/10.1109/MEDITEC.2016.7835381.

31. Multiple Linear Regression Analysis.

32. Enhancing Patient Safety. The Role of Clinical Engineering, a white paper prepared by the American College of Clinical Engineering, 2001. https://accenet.org/Pages/Default.aspx.

33. Hossain MA, Sharon SM, Rashid MA, Islam MR, Ahmad M. Necessity of clinical engineers to improve present health technology management in developing countries. Mod Appl Sci. 2015;9(12):220-33.

34. Kline J. Vice President of Client Services, Patient Care Technology Systems, 2019. Link available at: https://www.givainc.com/docs/ Case\%20Study\%20-\%20Giva\%20\&\%20PCTS.

35. Boatemaa MA. Hospital Equipment and its Management System: A Mini-Review. Curr Trends Biomedical Eng \& Biosci. 2017;6(2): CTBEB.MS.ID.555684):1-5.

36. Dickey DM. A Clinical Engineer's Approach to CMS Compliance, 2015. Link available at https://pdfs.semanticscholar.org.

37. Clinical Engineering Technologists: Link: https://www.kitasato-u. ac.jp/ahs/english/ce.html

38. Biomedical equipment technician. Link available at: http://bmy. tbmyo.marmara.edu.tr/en/biomedical-equipment-technician/

39. Ginsburg G. Human factors engineering: a tool for medical device evaluation in hospital procurement decision-making. J Biomed Inform. 2005;38:213-9.

40. Yousry AM, Ouda BK, Eldeib A. An integrated evaluation for the performance of clinical engineering department. 2014 36th Annual International Conference of the IEEE Engineering in Medicine and Biology Society. 2014, EMBC 2014. https://doi.org/10.1109/ EMBC.2014.6944281.

41. Zhang J, Johnson TR, Patel VL, Paige DL, Tate Kubose T. Using usability heuristics to evaluate patient safety of medical devices. J Biomed Inform. 2003;36(1-2):23-30. https://doi.org/10.1016/ S1532-0464(03)00060-1.

42. American Society of Healthcare Engineering. http://www.ashe.org/. Accessed July 30, 2015.

43. Mitchell PH, Lang NM. Framing the problem of measuring and improving healthcare quality: has the Quality Health Outcomes Model been useful. Med Care. 2004;42(II):4-11.

44. Hossain MA, Ahmad M, Yusuf MSU. Clinical engineering professional generation by interfacing public universities and health sectors of Bangladesh. 9th International Forum on Strategic Technology (IFOST), 2014.

Publisher's note Springer Nature remains neutral with regard to jurisdictional claims in published maps and institutional affiliations. 